\title{
Whether histologic subtyping affect the oncological outcomes of patients with papillary renal cell carcinoma: evidence from a systematic review and meta-analysis
}

\author{
Shengwei Xiong"^, Weijie Zhu\#, Xinfei Li, Yanfei Yu, Kunlin Yang, Lei Zhang, Yue Mi, Xuesong Li, \\ Liqun Zhou \\ Department of Urology, Peking University First Hospital, Institute of Urology, Peking University, National Urological Cancer Centre, Beijing, \\ China \\ Contributions: (I) Conception and design: S Xiong, Y Mi, X Li; (II) Administrative support: X Li, L Zhou; (III) Provision of study materials or \\ patients: Y Mi, X Li, L Zhou; (IV) Collection and assembly of data: S Xiong, W Zhu, X Li; (V) Data analysis and interpretation: S Xiong, W Zhu, Y \\ Yu, K Yang, L Zhang; (VI) Manuscript writing: All authors; (VII) Final approval of manuscript: All authors. \\ \#These authors contributed equally to this work. \\ Correspondence to: Yue Mi. Department of Urology, Peking University First Hospital, Institute of Urology, Peking University, National Urological \\ Cancer Centre, No. 8 Xishiku St, Xicheng District, Beijing 100034, China. Email: miyuebmu@126.com; Xuesong Li. Department of Urology, \\ Peking University First Hospital, Institute of Urology, Peking University, National Urological Cancer Centre, No. 8 Xishiku St., Xicheng District, \\ Beijing 100034, China. Email: pineneedle@sina.com.
}

Background: Whether the histologic subtype (type 1 and type 2) of papillary renal cell carcinoma (pRCC) is a tool to predict the prognosis is of great debate. This study is aimed to evaluate the prognostic significance of histologic subtype in patients with pRCC after surgery through a systematic review and meta-analysis.

Methods: We searched PubMed, the Web of Science, Cochrane library and EMBASE databases to identify studies published until January 20, 2021 according to the PRISMA (Preferred Reporting Items for Systematic Reviews and Meta-Analyses) guidelines. Studies were deemed eligible if they compared the overall survival (OS), cancer specific survival (CSS), recurrence-free survival (RFS) or disease-free survival (DFS) between patients with type 1 or type 2 pRCC. And the corresponding hazard ratios (HRs) and 95\% conference intervals (CIs) were collected for meta-analysis and further subgroup analysis.

Results: Overall 22 studies with a total of 4,494 patients were considered eligible and included for the systematic review and meta-analysis. The pooled results showed that type $2 \mathrm{pRCC}$ was associated with a worse OS (pooled HR 1.61, 95\% CI: 1.10-2.36, P=0.02) and CSS (pooled HR 1.59, 95\% CI: 1.00-2.51, P=0.05). However, the subgroup analysis yielded the same result as the initial analysis only when the HRs were extracted from univariate analysis. In studies with multivariate analysis, type $2 \mathrm{pRCC}$ was not statistically associated with a worse OS (pooled HR 1.22, 95\% CI: 0.97-1.53, P=0.27), CSS (pooled HR 1.16, 95\% CI: 0.67-2.00, P=0.60), and DFS (pooled HR 1.33, 95\% CI: 0.93-1.91, P=0.12) compared to type 1 pRCC.

Discussion: Histologic subtype is not an independent prognostic factor for patients with pRCC, although the result needs to be taken with caution. And studies with retrospective study design, larger sample size and longer follow-up period are required to verify these results.

Keywords: Papillary renal cell carcinoma (pRCC); histologic subtype; prognosis; meta-analysis

Submitted Apr 18, 2021. Accepted for publication Jun 29, 2021.

doi: $10.21037 /$ tau-21-329

View this article at: https://dx.doi.org/10.21037/tau-21-329

$\wedge$ ORCID: 0000-0003-4885-899X. 


\section{Introduction}

Papillary renal cell carcinoma (pRCC), the second largest subset of renal cell carcinoma (RCC) following clear cell RCC, accounts for $6-18 \%$ of all RCC cases. Histologically, pRCC is characterized by the presence of papillae and tubular structures together with the cores of fibrovascular tissues. And pRCC has two main subtypes: type 1 and type 2, which was first introduced by Delahunt and Eble in 1997 (1). Type 1 tumors have small cells containing scant pale cytoplasm and low-grade nuclei, and they usually have foamy macrophages within papillary cores. Whereas, type 2 tumors have abundant eosinophilic cytoplasm and large high-grade nuclei, and foamy macrophages are rare (2).

Since this histologic subtype of pRCC was proposed, some studies have demonstrated that type 1 and type 2 pRCC are clinically and biologically distinct. The worse prognosis of type $2 \mathrm{pRCC}$ has been observed, as patients with type 2 pRCC are diagnosed at a higher stage (3), and appears to be dominant in the patients of pRCC with inferior vena cava thrombus (4). Linehan et al. reported that type 1 pRCC was associated with MET alterations, whereas type 2 pRCC was characterized by activation of the NRF2-antioxidant response element pathway, and cyelindependent kinase inhibitor $2 \mathrm{~A} / \mathrm{B}(\mathrm{CDKN} 2 \mathrm{~A} / \mathrm{B})$ silencing and $\mathrm{CpG}$ island methylator phenotype, conveyed a poor prognosis (5). However, some studies reported that the histologic subtype of pRCC have no impact on oncological outcomes (6-8), and some studies even demonstrated that type 1 histology was associated with an adverse impact on the survival of pRCC patients (9). Whether the histologic subclassification of pRCC is a tool to predict the prognosis is of great debate.

Thus, we performed this systemic review and metaanalysis of the available data to improve our understanding of the histologic subtype associated with oncological outcomes of pRCC patients. We present the following article in accordance with the PRISMA reporting checklist (available at https://dx.doi.org/10.21037/tau-21-329).

\section{Methods}

\section{Search strategy}

This systematic review and meta-analysis were performed according to the Preferred Reporting Items for Systematic Reviews and Meta-Analyses (PRISMA) statement (10). A comprehensive literature search was conducted using electronic databases including PubMed, the Web of
Science, Cochrane library and EMBASE to identify studies published until January 20, 2021. Our study protocol has been registered in the International Prospective Register of Systematic Reviews database PROSPERO (CRD 42021231708).

The search terms used for the search were (("papillary renal cell carcinoma" OR "papillary renal cancer" OR "papillary kidney cancer") AND ("prognosis" OR "prognostic" OR "survival” OR "outcome”) AND ("subclassification" OR "subtype" OR "subtyping" OR "type")). We also manually screened the references lists of retrieved articles to identify potential eligible studies. Search results were independently reviewed by two investigators (SWX and WJZ) to decrease selection bias, and reasons for excluding ineligible literatures were noted. Disagreements were resolved via consensus with a third investigator.

\section{Inclusion and exclusion criteria}

We specified the required inclusion criteria by using the Population, Intervention, Comparator, Outcome, and Study design (PICOS) approach, according to the PRISMA guidelines. The studies were included if they compared the patients with pRCC (Population) who had undergone radical nephrectomy or partial nephrectomy (Intervention) to assess the prognostic impact of histological subtype (Comparator) on oncological outcomes (Outcome) using univariate and/or multivariable Cox regression analysis (Study design). The oncological outcomes consisted of overall survival (OS) and cancer specific survival (CSS), recurrence-free survival (RFS) and disease-free survival (DFS).

We excluded reviews, meta-analysis, letters, editorials, comments, conference abstracts, case reports and articles not published in English. In studies that shared duplicate cohort, the higher quality or the most recent one was selected. And studies provided no or insufficient data for estimating hazard ratios (HRs) and corresponding 95\% CIs were excluded.

\section{Data extraction and quality assessment}

The required data extracted from all eligible studies include: first author's name, year of publication, study design, recruitment region, recruitment period, number of patients, duration of follow-up, oncological outcomes (OS, CSS, RFS and DFS), HRs and corresponding 95\% CIs, that were used for prognostic analysis. If both multivariate and 
univariate analysis were reported, we chose the HRs and $95 \%$ CIs from the former. If multivariate analysis was not available, the HRs and 95\% CIs from univariate analysis was chosen. DFS and RFS have a similar meaning, that is the length of time after the surgery for a cancer ends that the patients survive without any signs or symptoms of that cancer. Thus, we integrated the data of RFS into DFS for final analysis.

The quality of included studies was assessed according to the Newcastle-Ottawa Scale (NOS) (11). In NOS, studies were judged on three broad perspectives (selection, comparability and exposure) with eight items. Each item was scored 1 or 2 . The scores varied from 0 to 9 . In our study, studies with scores greater than 6 were considered high quality. Low quality studies were excluded because it can distort the summary effect estimate. Both data extractions and quality assessments were performed independently by two reviewers (S.W.X. and W.J.Z.). And any discrepancies were addressed by a third reviewer and group discussion.

\section{Statistical analysis}

Forest plots were used to assess multivariate HRs and corresponding $95 \%$ CIs of OS, CSS, RFS, and DFS. The prognostic significance was evaluated by aggregating Cochran's Q-test and Higgins $\mathrm{I}^{2}$ statistics were used to estimate the presence of heterogeneity among the studies. Random-effects analysis was employed to pool data if statistical heterogeneity was indicated $\left(\mathrm{I}^{2}>50 \%\right.$ and/or $\mathrm{P}<0.05)$. Otherwise, a fixed-effect model was utilized. Subgroup analysis was performed, according to sample size, duration of follow-up and method of Cox analysis to explore the potential source of heterogeneity. Egger's test and Begg's test were examined to evaluate publication bias and to re-estimate the pooled effect of the unpublished studies when bias was indicated. And sensitivity analysis was applied to confirm the robustness of the results. $\mathrm{P}$ value less than 0.05 was considered statistically significant. The statistical analyses were done with Reviews Manager 5.3 (Cochrane Collaboration, Oxford, UK) or Stata 12.0 (STATA Corporation, College Station, TX, USA).

\section{Results}

\section{Study selection and characteristics}

A total of 682 articles were obtained from the initial databases, and 417 articles were excluded after reduplicative articles were removed. After primary screening, 384 studies, that published in non-English, not pRCC related articles, and non-original, abstract only and case report articles were excluded. Of the 33 articles selected for the full-text evaluation, 10 articles were excluded, because these studies provide not sufficient, not clear data or no hazard ratio value between histology type and oncological outcomes. Finally, 22 studies were considered eligible and included the in quantitative synthesis (meta-analysis), with a total of 4,494 cases. The detailed process of selection of studies for inclusion is shown in Figure 1.

The characteristics of included studies are presented in Table 1 (3,6-9,12-28). All included studies were in retrospective designs and were published between 2001 and 2020, and the patients were recruited ranged from 1970 to 2018 . The mean follow-up was $58.5 \pm 27.8$ months, except that two studies reported respective follow-up time according to the histologic subtype of pRCC. The median NOS score of included studies was 6 (range, 6 to 7).

\section{Overall survival}

Fourteen studies in a total of 2,976 patients with pRCC provided survival data on the association of histologic subtype and OS. Forest plot (Figure 2) indicated that type 2 pRCC was associated with a worse OS compared to type 1 pRCC (pooled HR 1.61, 95\% CI: 1.10-2.35). However, the Cochrane $\mathrm{Q}$ test (chi-square $=39.22, \mathrm{P}=0.0002)$ and $\mathrm{I}^{2}$ test $(67 \%)$ revealed significant heterogeneity. The sensitivity analysis confirmed the robustness of the results (Figure $3 A$ ).

To explore the potential source of heterogeneity, the subgroup analysis was conducted based on the analysis method, sample size and duration of follow-up (Table 2). Regarding analysis method, none statistically correlation was detected between histologic subtype and OS when using multivariate analysis (pooled HR 1.22, 95\% CI: $0.97-1.53, \mathrm{P}=0.27$ ). However, the results from studies only using univariable analysis indicated that type 2 pRCC was associated with a worse OS (pooled HR 2.73, 95\% CI: 1.78 4.19, $\mathrm{P}<0.01$ ). Similarly, there was no obvious relationship between histologic subtype and OS when the sample size was greater than $200(\mathrm{P}=0.29)$, but the results from studies with sample size less than 200 indicated that type 2 was associated with a worse $\mathrm{OS}(\mathrm{P}=0.04)$. In addition, there was no significant association between histologic subtype and OS whether the mean duration of follow-up less than 60 months $(\mathrm{P}=0.08)$ or more than 60 months $(\mathrm{P}=0.11)$. 


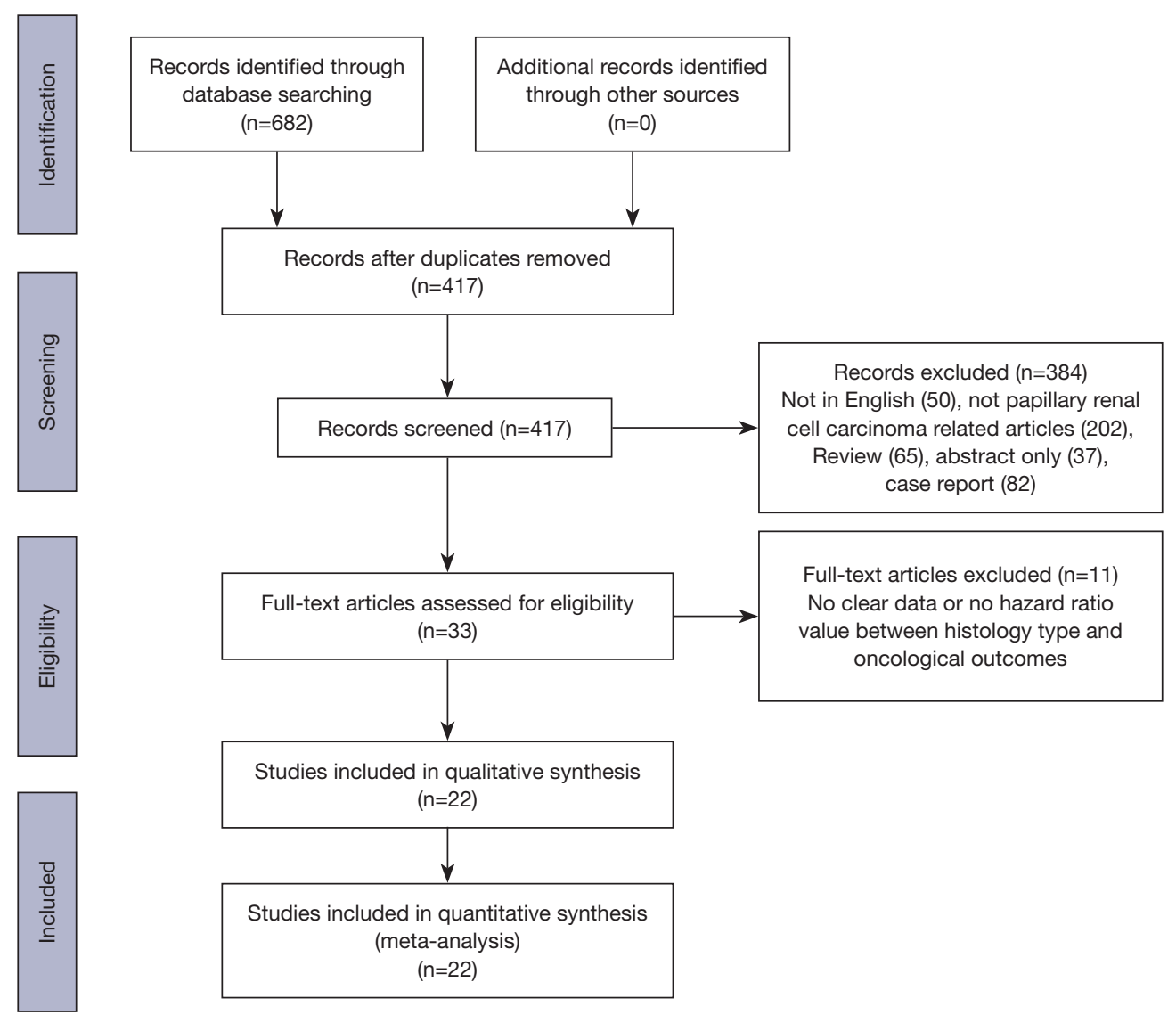

Figure 1 PRISMA flow chart of study selection process.

\section{Cancer specific survival}

A total of 12 studies with 2,724 patients with pRCC provided survival data on the association of histologic subtype and CSS. The pooled HR for these studies was 1.59 (95\% CI: 1.00-2.51) (Figure 2). There was moderate statistical heterogeneity among the studies (chisquare $\left.=22.25, \mathrm{P}=0.02 ; \mathrm{I}^{2}=51 \%\right)$. The sensitivity analysis confirmed the robustness of the results (Figure 3B).

The subgroup analysis was also performed when concerning CSS (Table 2). Regarding analysis method, no relationship was detected between histologic subtype and CSS when using multivariate analysis (pooled HR 1.16, 95\% CI: 0.67-2.00, $\mathrm{P}=0.60$ ). However, the merged results of univariable analysis validated that type $2 \mathrm{pRCC}$ was an unfavorable prognostic factor of CSS (pooled HR 2.17, 95\% CI: 1.09-4.34, P=0.03). Similarly, there was no obvious relationship between pRCC subtype and CSS when the sample size was greater than $200(\mathrm{P}=0.73)$, but the merged results of studies with sample size less than 200 validated that type 2 was associated with a worse CSS $(\mathrm{P}=0.01)$. Furthermore, the subgroup analyses classified by duration of follow-up validated that no significant association between pRCC subtype and CSS whether the mean duration of follow-up less than 60 months $(\mathrm{P}=0.21)$ or more than 60 months $(\mathrm{P}=0.12)$.

\section{Disease free survival}

Among the 22 studies, 3 reported DFS, 2 covered relapse free survival (RFS). All these 5 studies with 1,369 patients were integrated into the meta-analysis of DFS, and the corresponding HRs and $95 \%$ CIs was all chosen from multivariate analysis. As shown in Figure 2C, the pooled HR was 1.33 (95\% CI, 0.93-1.91), indicating that there is no significant effect of pRCC subtype on DFS. And there was no obvious heterogeneity among studies (chi-square $=3.86$, $\mathrm{P}=0.42 ; \mathrm{I}^{2}=0 \%$ ). And the sensitivity analysis confirmed the robustness of the results (Figure 3C). 
Table 1 The characteristics of included studies

\begin{tabular}{|c|c|c|c|c|c|c|c|c|c|}
\hline Author & Year & Country & Center & $\begin{array}{l}\text { Recruitment } \\
\text { period }\end{array}$ & $\begin{array}{l}\text { No. of patients, } \\
\text { type } 1 / \text { type } 2, n\end{array}$ & $\begin{array}{l}\text { Median follow-up, } \\
\text { months }\end{array}$ & $\begin{array}{l}\text { Oncological } \\
\text { outcome, HR }\end{array}$ & $\begin{array}{c}\text { Cox } \\
\text { Analysis }\end{array}$ & $\begin{array}{l}\text { NOS } \\
\text { score }\end{array}$ \\
\hline Delahunt (12) & 2001 & New Zealand & Single & N.A. & $52 / 16$ & 60 & os & $M$ & 6 \\
\hline Allory (13) & 2003 & France & Single & 1992-1998 & $26 / 13$ & 43 & os & M & 6 \\
\hline Gontero (16) & 2008 & Italy & Single & 1989-2002 & $14 / 31$ & 84.5 & os & $U, M$ & 7 \\
\hline Margulis (17) & 2008 & USA & Single & N.A. & $62 / 61$ & 22.2 & css & U & 6 \\
\hline Klatte (18) & 2009 & USA & Single & 1985-2007 & $51 / 107$ & 38 & DFS & $U, M$ & 6 \\
\hline Hutterer (22) & 2013 & Austria & Single & 1984-2007 & $87 / 89$ & 68.3 & css & M & 6 \\
\hline Cornejo (23) & 2015 & USA & Single & 1984-2010 & $112 / 42$ & 73.9 & os, css & U & 6 \\
\hline Ledezma (7) & 2016 & USA & multiply & 2002-2012 & $373 / 253$ & 41 & OS, CSS, RFS & $U, M$ & 8 \\
\hline $\mathrm{Ha}(24)$ & 2017 & Korea & multiply & 1988-2011 & $118 / 156$ & 38 & OS, CSS, RFS & $U, M$ & 7 \\
\hline Bigot (6) & 2016 & French & multiply & 2004-2014 & $369 / 117$ & 35 & cSs & $U$ & 6 \\
\hline Bellut (25) & 2017 & Germany & multiply & 1993-2007 & $113 / 39$ & 98.2 & OS, css & $U$ & 6 \\
\hline Polifka (8) & 2019 & Germany & multiply & 1993-2007 & $246 / 130$ & 38 & OS & $\mathrm{U}, \mathrm{M}$ & 6 \\
\hline
\end{tabular}

*, the follow-up time is respective according to the histologic subtype of PRCC, that is type 1/type 2. CSS, cancer-specific survival; DFS, disease-free survival; M, multivariate analysis; N.A., not available; OS, overall survival; NOS, Newcastle-Ottawa scale; RFS, recurrencefree survival; $U$, univariate analysis.

\section{Publication bias}

The Begg's test and Egger's linear regression test were performed to evaluate the publication bias of included studies, and the Begg's funnel plots were shown in Figure 4. No significant publication bias was found for OS ( $\mathrm{P}=0.511$ for Begg's test and $\mathrm{P}=0.357$ for Egger's test), CSS ( $\mathrm{P}=0.451$ for Begg's test and $\mathrm{P}=0.337$ for Egger's test) and DFS $(\mathrm{P}=0.806$ for Begg's test and $\mathrm{P}=0.926$ for Egger's test).

\section{Discussion}

Some previous studies have demonstrated that type 2 pRCC was associated with worse survival than type $1(3,13,25,29)$. However, the conclusion must be taken with caution, as these studies may be limited by sample size, short duration of follow-up, or the infrequency of death related to pRCC $(25,26)$. And some recent studies hold the view that histological subtype is not an independent prognostic marker (9). Thus, we conducted this meta-analysis to evaluate synthetically the prognostic significance of pRCC subtype.

The pooled analysis using available survival data from 14 studies in a total of 2,976 patients found that type 2 pRCC was associated with a worse OS compared to type 


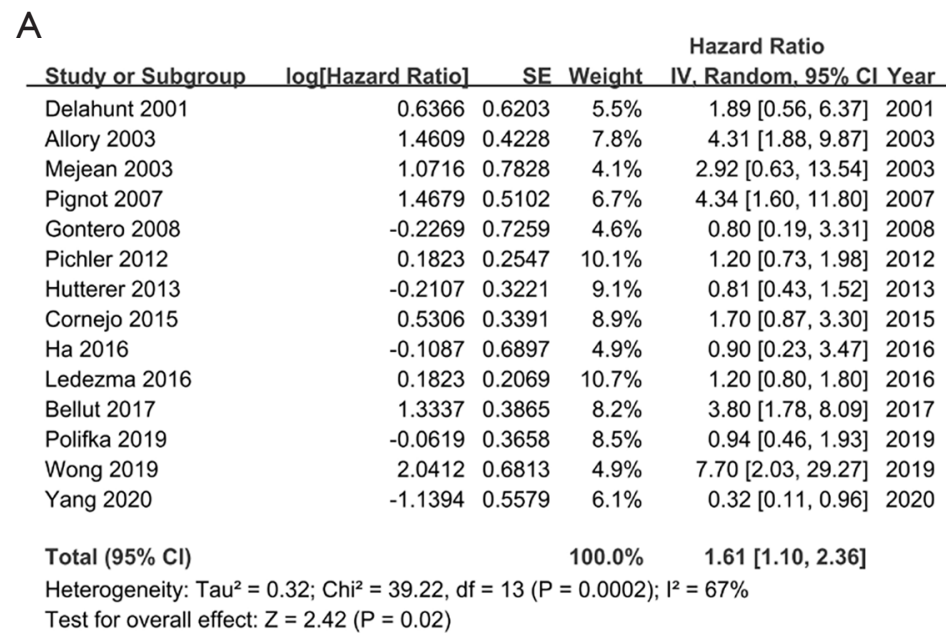

B

Study

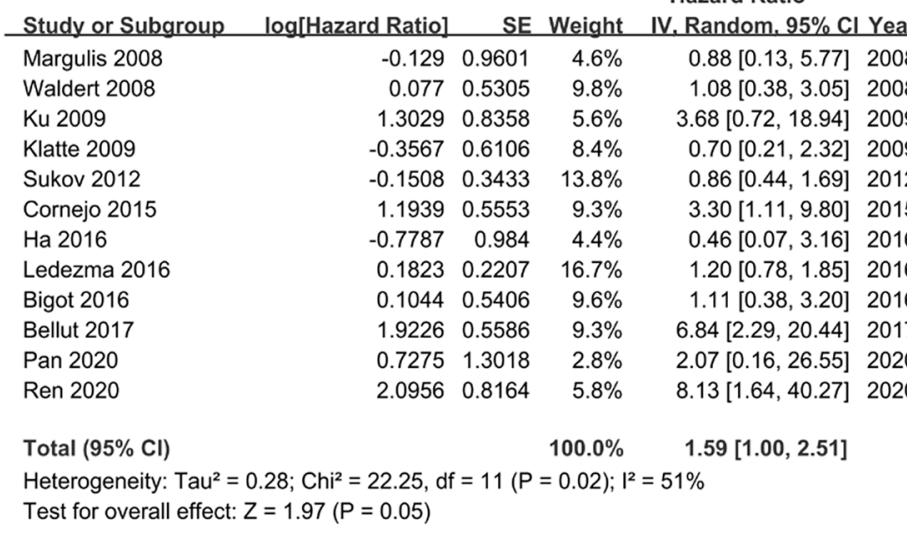

Test for overall effect: $Z=1.97(P=0.05)$

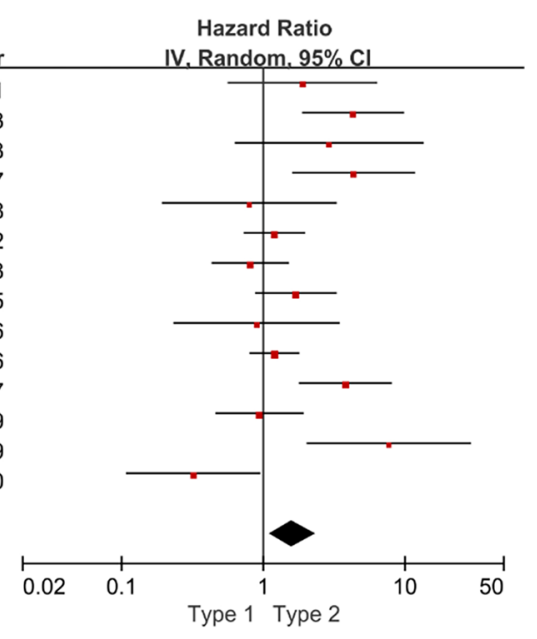

C

\begin{tabular}{|c|c|c|c|c|c|c|c|c|c|c|}
\hline Study or Subgroup & log[Hazard Ratio] & $\mathrm{SE}$ & Weight & $\begin{array}{l}\text { Hazard Ratio } \\
\text { IV. Random, } 95 \% \mathrm{CI} \text { Year }\end{array}$ & & & $\begin{array}{r}\text { Hazard } \\
\text { IV. Rando }\end{array}$ & Ratio & & \\
\hline Pignot 2007 & 1.1694 & 0.5639 & $10.6 \%$ & $3.22[1.07,9.72] 2007$ & & & & & & \\
\hline Pichler 2012 & 0.1823 & 0.2678 & $47.0 \%$ & $1.20[0.71,2.03] 2012$ & & & & & & \\
\hline На 2016 & 0.0478 & 0.6405 & $8.2 \%$ & $1.05[0.30,3.68] 2016$ & & & & & & \\
\hline Ledezma 2016 & 0.3365 & 0.3347 & $30.1 \%$ & $1.40[0.73,2.70] 2016$ & & & & - & & \\
\hline Yang 2020 & -0.6539 & 0.8971 & $4.2 \%$ & $0.52[0.09,3.02] 2020$ & & & & & & \\
\hline Total $(95 \% \mathrm{Cl})$ & & & $100.0 \%$ & $1.33[0.93,1.91]$ & & & & & & \\
\hline \multicolumn{5}{|c|}{$\begin{array}{l}\text { Heterogeneity: } \text { Tau }^{2}=0.00 ; \mathrm{Chi}^{2}=3.86, \mathrm{df}=4(P=0.42) ;\left.\right|^{2}=0 \% \\
\text { Test for overall effect: } Z=1.56(P=0.12)\end{array}$} & 0.02 & 0.1 & Type ${ }^{1}$ & Type 2 & 10 & 50 \\
\hline
\end{tabular}

Figure 2 Forest plot of histologic subtype associated with oncological outcomes of pRCC patients. (A) Overall survival; (B) cancer specific survival; (C) disease-free survival.

1 pRCC (pooled HR 1.61, 95\% CI: 1.10-2.35, P=0.02). Nevertheless, the subgroup analysis did not yield the same result as the initial analysis. The pooled findings from studies with multivariate analysis $(\mathrm{P}=0.27)$, more than 200 cases and duration of follow-up more than 60 months $(\mathrm{P}=0.29)$ showed that there is no statistically significant adverse effect of type 2 pRCC on OS (Table 2). The same results emerged when concerning CSS. In univariate Cox regression analysis, tumour pathologic features such as pathological TNM stage, nucleolar grade, and tumour size are not included. And lymphovascular invasion (LVI), necrosis, multifocality, sarcomatoid structure, presence of foamy macrophages, psammomatous calcification were also proposed to have a prognostic impact on pRCC, and these 
A

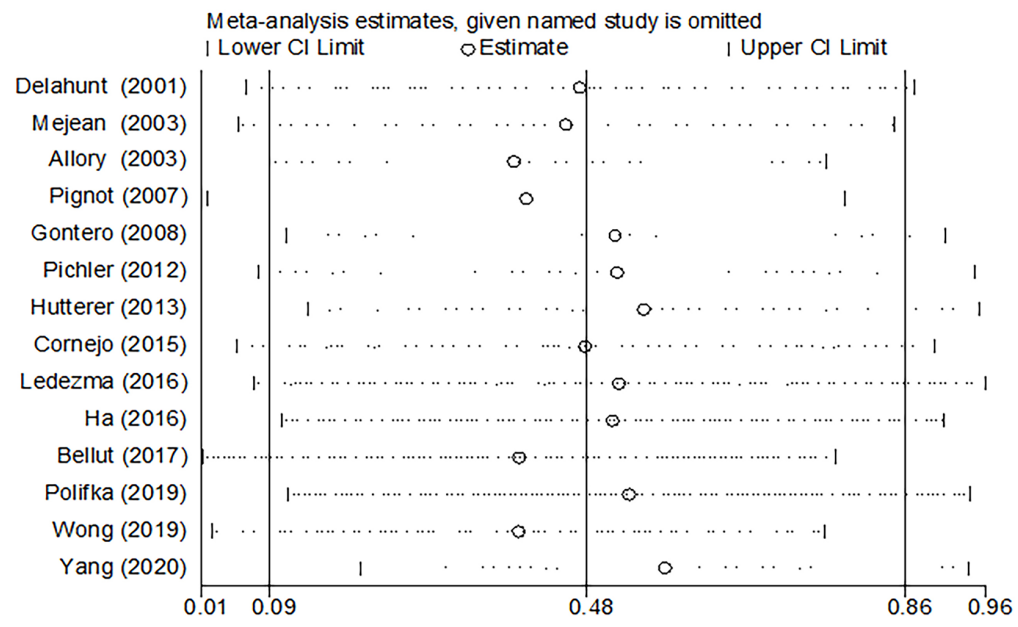

B

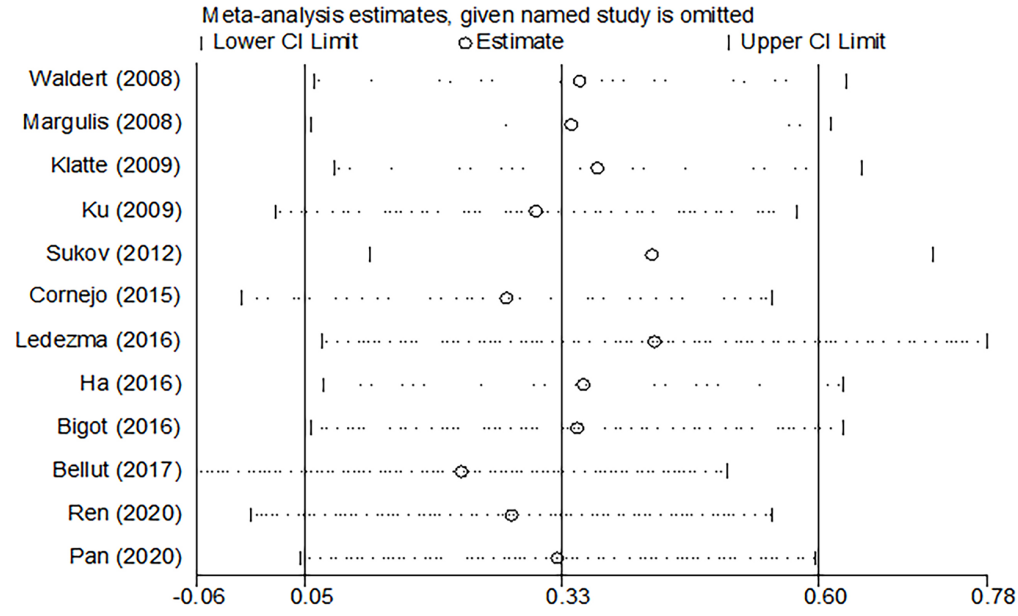

C

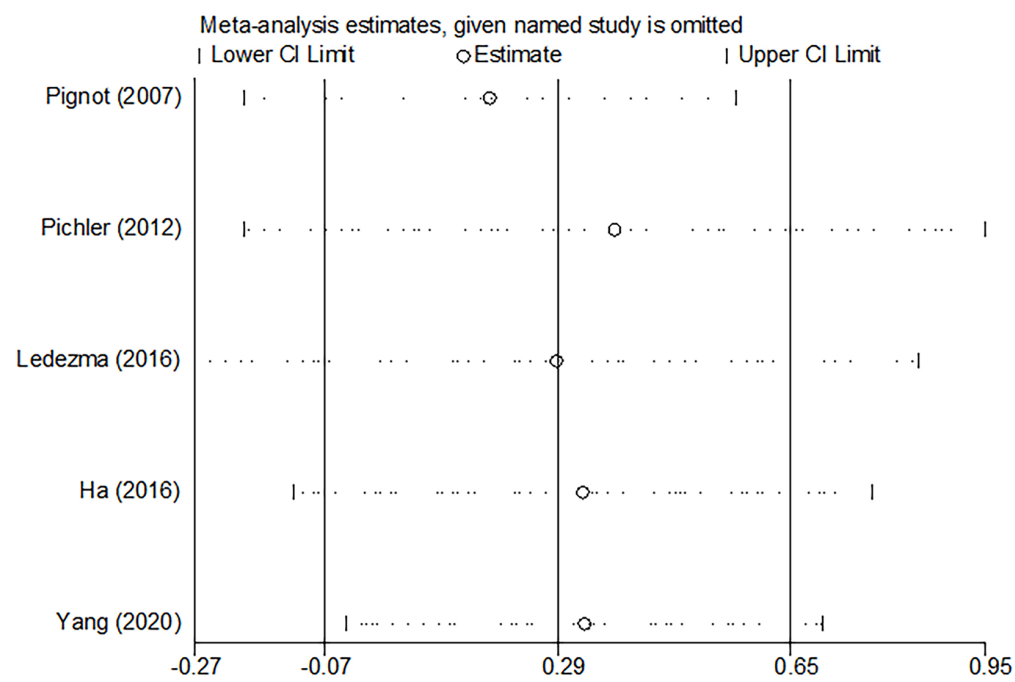

Figure 3 Sensitivity analysis of overall survival (A), cancer specific survival (B) and disease-free survival (C). 
Table 2 Subgroup analyses of OS and CSS

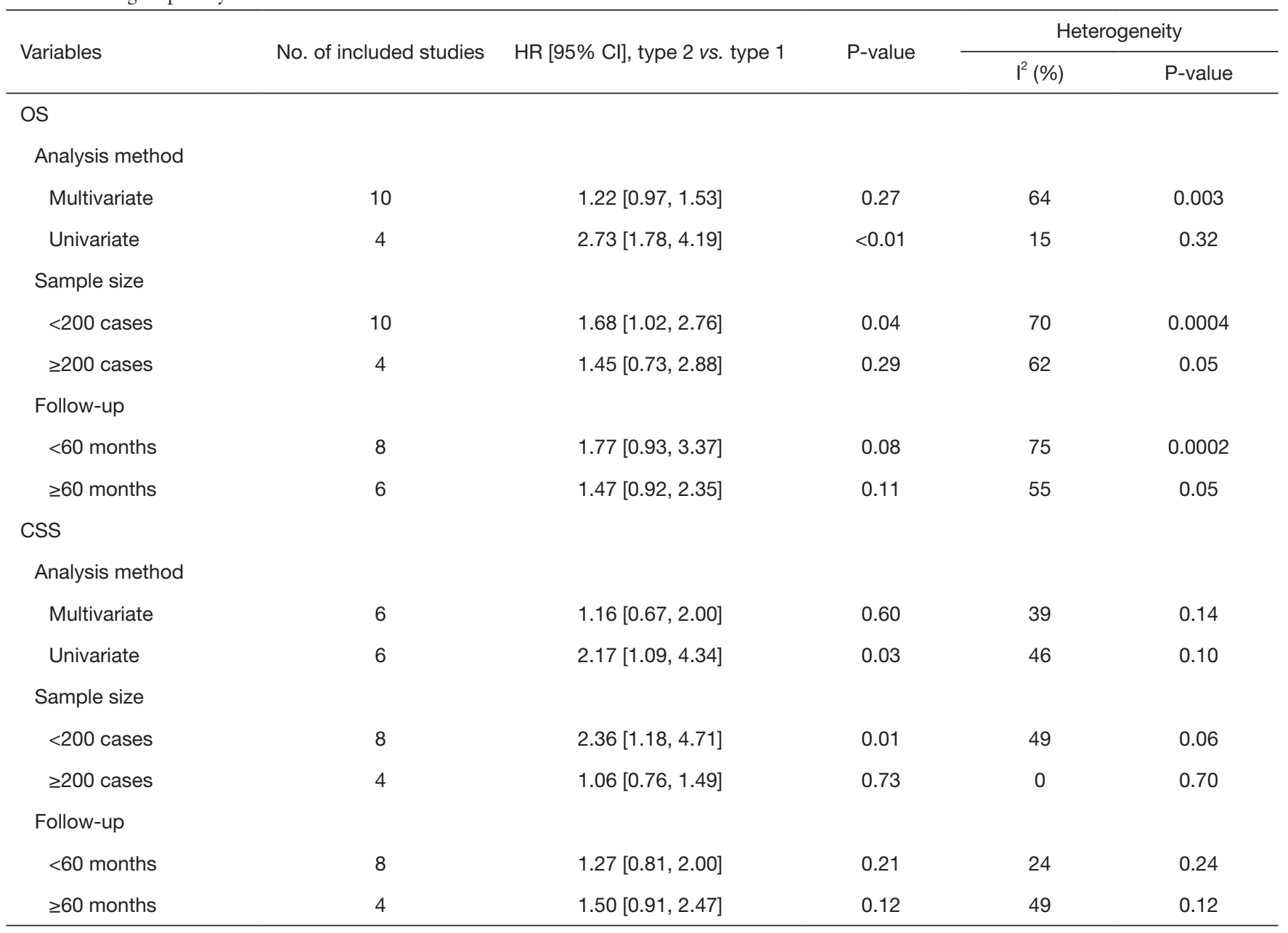

CSS, cancer-specific survival; OS, overall survival; HR, hazard ratio.

features were usually associated with aggressive behavior $(21,22,30,31)$. Based on our findings from meta-analysis, we believe that histological subtype is not an independent prognostic factor for pRCC. And pooled results from studies with larger sample size ( $\geq 200$ cases) and longer follow-up period ( $\geq 60$ months) further confirmed this conclusion.

$\mathrm{Ku}$ et al. reported that type $2 \mathrm{pRCC}$ had larger tumour size, advanced stage and poorer grade, and more frequent necrosis and LVI compared with type 1 pRCC (19). However, there was no statistically significant difference between histological subtype and CSS probability (19). Bigot et al. reported that patients with localized type $1 \mathrm{pRCC}$ had a statistically equal CSS compared to localized type $2 \mathrm{pRCC}$ (vs. type $2, \mathrm{HR}=0.9, \mathrm{P}=0.89$ ), while metastatic type $1 \mathrm{pRCC}$ had a poorer survival than metastatic type $2 \mathrm{pRCC}(6)$. The largest pRCC subtype cohort till now was presented by Ledezma et al. (7), and the authors only included localized type $1(n=373)$ and type $2(n=253)$ pRCC. And they reported that type 2 pRCC patients presented with larger tumor size, are more frequent synchronous nodal metastases and venous tumor thrombus than type 1 pRCC patients, but pRCC subtype is neither an independent prognostic predictor of OS $(\mathrm{P}=0.5)$, CSS $(\mathrm{P}=0.4)$, or $\mathrm{RFS}(\mathrm{P}=0.3)$ in multivariable analysis (7). On the other hand, pathological T stage, lymph node involvement, presence of metastases, International Society of Urological Pathology (ISUP) grade and Fuhrman grade were verified as independent prognostic factors of oncological outcomes $(9,17,32)$. To further assess the prognosis with highly accurate, Klatte et al. developed a prognostic Nomogram to predict disease specific survival (DSS) of pRCC patients (33). Incidental detection, 

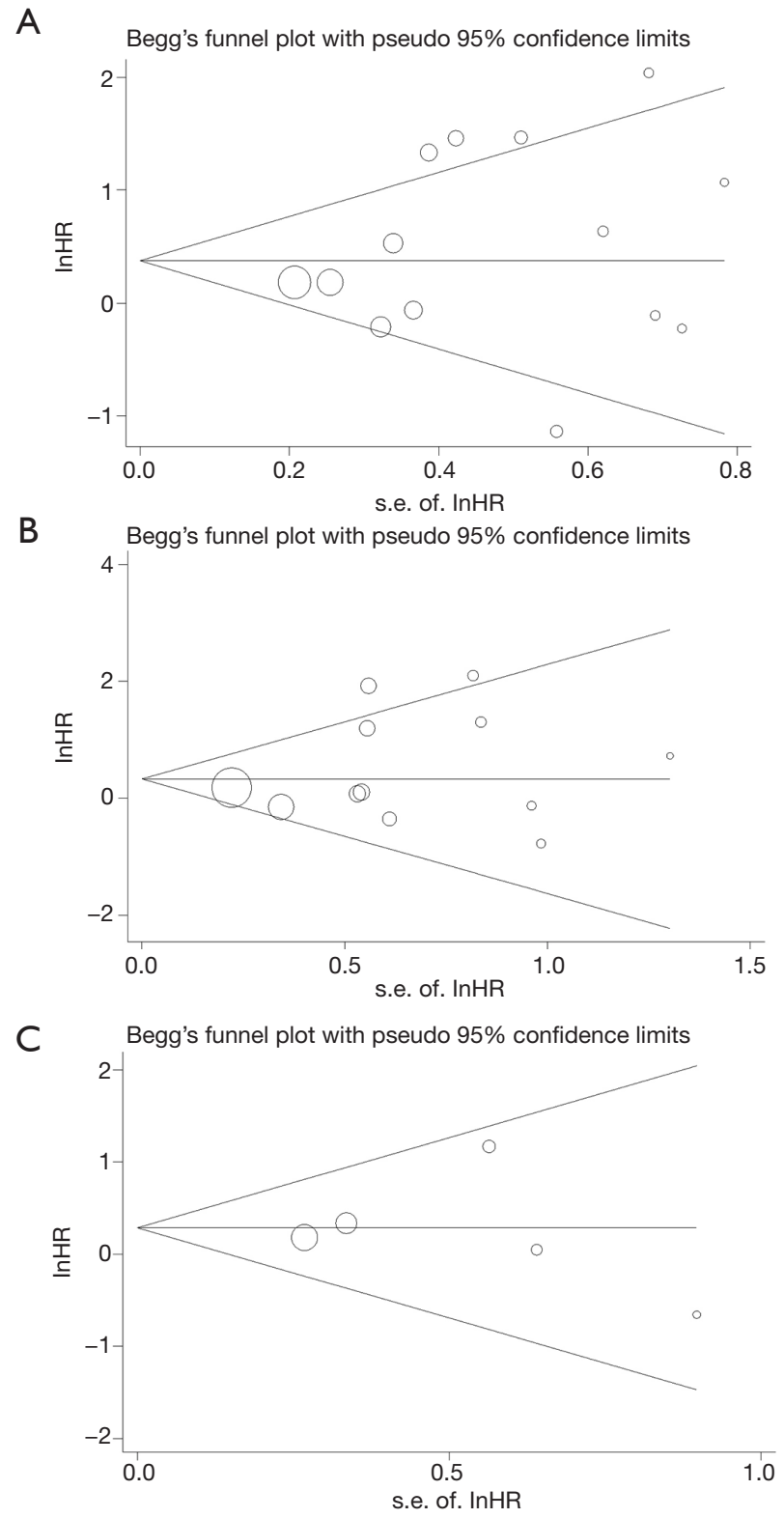

Figure 4 Publication bias of overall survival (A), cancer specific survival (B) and disease-free survival (C) based on Begg's funnel plot.

pathological TNM stage, LVI and tumor necrosis extent were retained as independent prognostic factors of DSS, and these factors formed the basis of the nomogram with an externally validated accuracy of $94 \%$ (33).

The contradictory views on whether histologic subtype is a prognostic predictor of pRCC may also attribute to the low mortality of pRCC. Alomari et al. demonstrated that both type 1 and type 2 pRCC appear to have excellent prognosis when diagnosed at early stage based on long follow-up data (mean 60 months) (34). They identified a total of 144 cases (including 71 type and 46 type 2), and only 2 cases died of pRCC. And Yang et al. included 185 patients in their study, only 2 patients (1.1\%) died of metastatic pRCC (9). Given this situation, we suggest using DFS to reflect the prognosis of pRCC, especially when disease-specific mortality was unavailable in retrospective analysis. And in this metaanalysis, the pooled $\mathrm{HR}(1.33, \mathrm{P}=0.12)$ from 5 studies also showed that pRCC subtype was not associated with DFS in multivariable analysis (Figure 2C).

Recently, classification of pRCC has undergone further evolution, as there is a proportion of pRCC cases that do not meet all the morphologic criteria for either type 1 or type 2 pRCC. These tumors were named as mixed, or not otherwise specified (NOS) (35). Saleeb proposed a new pRCC subtype from NOS cases, type 3 pRCC, and it has overlapping morphology between type 1 and type 2 pRCC (36). The authors reported and type 3 pRCC had near equal DFS compared with type $1 \mathrm{pRCC}(\mathrm{P}=0.057)$. But this new pRCC subtype was corresponding to a specific group of type 2 pRCC cohort that had been previously described by Marsaud et al. (37). Thus, it is important to further stratify the pRCC into subtypes combined morphologic, genetic, molecular and immunophenotypic features, which could potentially contribute to survival prediction and clinical management of pRCC.

The present meta-analysis showed that the histologic subclassification of pRCC may not provide prognostic significance. And when a patient is diagnosed with a type 2 pRCC, the urologists should attach more importance on TNM stage, nucleolar grade, and other pathologic features such as LVI, necrosis, multifocality, and sarcomatoid structure, which had been proposed to associate with aggressive behaviors and have adverse impact on pRCC prognosis $(20,32,33)$. And the Immunohistochemical and molecular analysis should be performed for further accurate subtyping.

There are some limitations in this study. The main limitation is that all the included cohorts are retrospective and most included cohorts are relatively small, which may influence the accuracy of the results when in practice. And majority of the recruited studies usually include mainly type 1 patients and patients with type 2 pRCC are relatively scarce. In addition, we recruited some studies published around the year of 2000. The included patients from these studies might be treated before the year of 1997, although with revision of histological subtype, a selection bias could be introduced. 


\section{Conclusions}

To our best knowledge, we conducted the first meta-analysis to comprehensively evaluate the association between histological subtype and oncological outcomes of pRCC. Based on our meta-analysis, type 2 pRCC was associated with worse OS and CSS than type $1 \mathrm{pRCC}$ in univariable analysis, whereas, type 2 pRCC was not statistically associated with worse OS, CSS and DFS than type $1 \mathrm{pRCC}$ in multivariable analysis, although these results need to be taken with caution. And studies with retrospective study design, larger sample size and longer follow-up period are required to verify these results.

\section{Acknowledgments}

Funding: None.

\section{Footnote}

Reporting Checklist: The authors have completed the PRISMA reporting checklist. Available at https://dx.doi. org/10.21037/tau-21-329

Conflicts of Interest: All authors have completed the ICMJE uniform disclosure form (available at https://dx.doi. org/10.21037/tau-21-329). The authors have no conflicts of interest to declare.

Ethical Statement: The authors are accountable for all aspects of the work in ensuring that questions related to the accuracy or integrity of any part of the work are appropriately investigated and resolved.

Open Access Statement: This is an Open Access article distributed in accordance with the Creative Commons Attribution-NonCommercial-NoDerivs 4.0 International License (CC BY-NC-ND 4.0), which permits the noncommercial replication and distribution of the article with the strict proviso that no changes or edits are made and the original work is properly cited (including links to both the formal publication through the relevant DOI and the license). See: https://creativecommons.org/licenses/by-nc-nd/4.0/.

\section{References}

1. Delahunt B, Eble JN. Papillary renal cell carcinoma: a clinicopathologic and immunohistochemical study of 105 tumors. Mod Pathol 1997;10:537-44.

2. Warrick JI, Tsodikov A, Kunju LP, et al. Papillary renal cell carcinoma revisited: a comprehensive histomorphologic study with outcome correlations. Hum Pathol 2014;45:1139-46.

3. Mejean A, Hopirtean V, Bazin JP, et al. Prognostic factors for the survival of patients with papillary renal cell carcinoma: meaning of histological typing and multifocality. J Urol 2003;170:764-7.

4. Kim KH, You D, Jeong IG, et al. Type II papillary histology predicts poor outcome in patients with renal cell carcinoma and vena cava thrombus. BJU Int 2012;110:E673-8.

5. Cancer Genome Atlas Research Network; Linehan WM, Spellman PT, et al. Comprehensive Molecular Characterization of Papillary Renal-Cell Carcinoma. N Engl J Med 2016;374:135-45.

6. Bigot P, Bernhard JC, Gill IS, et al. The subclassification of papillary renal cell carcinoma does not affect oncological outcomes after nephron sparing surgery. World J Urol 2016;34:347-52.

7. Ledezma RA, Negron E, Paner GP, et al. Clinically localized type 1 and 2 papillary renal cell carcinomas have similar survival outcomes following surgery. World J Urol 2016;34:687-93.

8. Polifka I, Agaimy A, Herrmann E, et al. High proliferation rate and TNM stage but not histomorphological subtype are independent prognostic markers for overall survival in papillary renal cell carcinoma. Hum Pathol 2019;83:212-23.

9. Yang C, Shuch B, Kluger H, et al. High WHO/ISUP Grade and Unfavorable Architecture, Rather Than Typing of Papillary Renal Cell Carcinoma, May Be Associated With Worse Prognosis. Am J Surg Pathol 2020;44:582-93.

10. Liberati A, Altman DG, Tetzlaff J, et al. The PRISMA statement for reporting systematic reviews and meta-analyses of studies that evaluate health care interventions: explanation and elaboration. PLoS Med 2009;6:e1000100.

11. Stang A. Critical evaluation of the Newcastle-Ottawa scale for the assessment of the quality of nonrandomized studies in meta-analyses. Eur J Epidemiol 2010;25:603-5.

12. Delahunt B, Eble JN, McCredie MR, et al. Morphologic typing of papillary renal cell carcinoma: comparison of 
growth kinetics and patient survival in 66 cases. Hum Pathol 2001;32:590-5.

13. Allory Y, Ouazana D, Boucher E, et al. Papillary renal cell carcinoma. Prognostic value of morphological subtypes in a clinicopathologic study of 43 cases. Virchows Arch 2003;442:336-42.

14. Pignot G, Elie C, Conquy S, et al. Survival analysis of 130 patients with papillary renal cell carcinoma: prognostic utility of type 1 and type 2 subclassification. Urology 2007;69:230-5.

15. Waldert M, Haitel A, Marberger M, et al. Comparison of type I and II papillary renal cell carcinoma (RCC) and clear cell RCC. BJU Int 2008;102:1381-4.

16. Gontero P, Ceratti G, Guglielmetti S, et al. Prognostic factors in a prospective series of papillary renal cell carcinoma. BJU Int 2008;102:697-702.

17. Margulis V, Tamboli P, Matin SF, et al. Analysis of clinicopathologic predictors of oncologic outcome provides insight into the natural history of surgically managed papillary renal cell carcinoma. Cancer 2008;112:1480-8

18. Klatte T, Pantuck AJ, Said JW, et al. Cytogenetic and molecular tumor profiling for type 1 and type 2 papillary renal cell carcinoma. Clin Cancer Res 2009;15:1162-9.

19. $\mathrm{Ku} \mathrm{JH}$, Moon KC, Kwak C, et al. Is there a role of the histologic subtypes of papillary renal cell carcinoma as a prognostic factor? Jpn J Clin Oncol 2009;39:664-70.

20. Sukov WR, Lohse CM, Leibovich BC, et al. Clinical and pathological features associated with prognosis in patients with papillary renal cell carcinoma. J Urol 2012;187:54-9.

21. Pichler M, Hutterer GC, Chromecki TF, et al. Presence and extent of histological tumour necrosis is an adverse prognostic factor in papillary type 1 but not in papillary type 2 renal cell carcinoma. Histopathology 2013;62:219-28.

22. Hutterer GC, Pichler M, Chromecki TF, et al. Tumourassociated macrophages might represent a favourable prognostic indicator in patients with papillary renal cell carcinoma. Histopathology 2013;63:309-15.

23. Cornejo KM, Dong F, Zhou AG, et al. Papillary renal cell carcinoma: correlation of tumor grade and histologic characteristics with clinical outcome. Hum Pathol 2015;46:1411-7.

24. Ha YS, Chung JW, Choi SH, et al. Clinical Significance of Subclassification of Papillary Renal Cell Carcinoma:
Comparison of Clinicopathologic Parameters and Oncologic Outcomes Between Papillary Histologic Subtypes 1 and 2 Using the Korean Renal Cell Carcinoma Database. Clin Genitourin Cancer 2017;15:e181-6.

25. Bellut J, Bertz S, Nolte E, et al. Differential prognostic value of MYC immunohistochemistry in subtypes of papillary renal cell carcinoma. Sci Rep 2017;7:16424.

26. Wong ECL, Di Lena R, Breau RH, et al. Morphologic subtyping as a prognostic predictor for survival in papillary renal cell carcinoma: Type 1 vs. type 2 . Urol Oncol 2019;37:721-6.

27. Ren W, Gao X, Zhang X, et al. Prognostic factors for the survival of patients with papillary renal cell carcinoma after surgical management. Clin Transl Oncol 2020;22:725-33.

28. Pan H, Ye L, Zhu Q, et al. The effect of the papillary renal cell carcinoma subtype on oncological outcomes. Sci Rep 2020;10:21073.

29. Le X, Wang XB, Zhao H, et al. Comparison of clinicopathologic parameters and oncologic outcomes between type 1 and type 2 papillary renal cell carcinoma. BMC Urol 2020;20:148.

30. Warrick JI, Tsodikov A, Kunju LP, et al. Papillary renal cell carcinoma revisited: a comprehensive histomorphologic study with outcome correlations. Hum Pathol 2014;45:1139-46.

31. Delahunt B, Cheville JC, Martignoni G, et al. The International Society of Urological Pathology (ISUP) grading system for renal cell carcinoma and other prognostic parameters. Am J Surg Pathol 2013;37:1490-504.

32. Zucchi A, Novara G, Costantini E, et al. Prognostic factors in a large multi-institutional series of papillary renal cell carcinoma. BJU Int 2012;109:1140-6.

33. Klatte T, Remzi M, Zigeuner RE, et al. Development and external validation of a nomogram predicting disease specific survival after nephrectomy for papillary renal cell carcinoma. J Urol 2010;184:53-8.

34. Alomari AK, Nettey OS, Singh D, et al. Clinicopathological and immunohistochemical characteristics of papillary renal cell carcinoma with emphasis on subtyping. Hum Pathol 2015;46:1418-26.

35. Saleeb RM, Plant P, Tawedrous E, et al. Integrated Phenotypic/Genotypic Analysis of Papillary Renal Cell Carcinoma Subtypes: Identification of Prognostic Markers, Cancer-related Pathways, and Implications for Therapy. Eur Urol Focus 2018;4:740-8. 
36. Saleeb RM, Brimo F, Farag M, et al. Toward Biological Subtyping of Papillary Renal Cell Carcinoma With Clinical Implications Through Histologic, Immunohistochemical, and Molecular Analysis. Am J Surg Pathol 2017;41:1618-29.

Cite this article as: Xiong S, Zhu W, Li X, Yu Y, Yang K, Zhang L, Mi Y, Li X, Zhou L. Whether histologic subtyping affect the oncological outcomes of patients with papillary renal cell carcinoma: evidence from a systematic review and metaanalysis. Transl Androl Urol 2021;10(8):3255-3266. doi: 10.21037/ tau-21-329
37. Marsaud A, Dadone B, Ambrosetti D, et al. Dismantling papillary renal cell carcinoma classification: The heterogeneity of genetic profiles suggests several independent diseases. Genes Chromosomes Cancer 2015;54:369-82. 